\title{
ASSOCIATIONS BETWEEN POLYMORPHISMS IN THE SOLUTE CARRIER FAMILY 6 MEMBER 3 AND THE MYELIN BASIC PROTEIN GENE AND POSTTRAUMATIC STRESS DISORDER
}

\author{
Mirnesa Muminovic Umihanic ${ }^{1}$, Romana Babic ${ }^{2}$, Nermina Kravic ${ }^{3,4}$, Esmina Avdibegovic ${ }^{3,4}$, \\ Alma Dzubur Kulenovic ${ }^{5}$, Ferid Agani ${ }^{6}$, Miro Jakovljevic ${ }^{7}$, Dragan Babic ${ }^{2}$, Abdulah Kucukalic ${ }^{5}$, \\ Sabina Kucukalic ${ }^{5}$, Emina Sabic Dzananovic ${ }^{5}$, Alma Bravo Mehmedbasic ${ }^{5}$, Aferdita Goci Uka ${ }^{8}$, \\ Shpend Haxhibeqiri ${ }^{9}$, Blerina Hoxha ${ }^{6}$, Valdete Haxhibeqiri ${ }^{10}$, Branka Aukst Margetic ${ }^{11}$, \\ Nenad Jaksic ${ }^{7}$, Ana Cima Franc ${ }^{7}$, Dusko Rudan ${ }^{7}$, Marko Pavlović $^{2}$, Elma Feric Bojic ${ }^{12}$, \\ Damir Marjanovic ${ }^{12}$, Nada Bozina ${ }^{13}$, Christiane Ziegler $^{14}$, Christiane Wolf $^{14}$, Bodo Warrings ${ }^{14}$, \\ Katharina Domschke ${ }^{14}$, Jürgen Deckert ${ }^{14}$ \& Osman Sinanovic ${ }^{4}$ \\ ${ }^{I}$ Community Health Center Zivinice, Živinice, Bosnia and Herzegovina \\ ${ }^{2}$ Department of Psychiatry, University Clinical Center of Mostar, Mostar, Bosnia and Herzegovina \\ ${ }^{3}$ Department of Psychiatry, University Clinical Center of Tuzla, Tuzla, Bosnia and Herzegovina \\ ${ }^{4}$ School of Medicine, University of Tuzla, Tuzla, Bosnia and Herzegovina \\ ${ }^{5}$ Department of Psychiatric, Clinical Center University of Sarajevo, Sarajevo, Bosnia and Herzegovina \\ ${ }^{6}$ Faculty of Medicine, University Hasan Prishtina, Prishtina, Kosovo \\ ${ }^{7}$ Department of Psychiatry, University Hospital Center Zagreb, Zagreb, Croatia \\ ${ }^{8}$ Department of Psychiatry, University Clinical Center of Kosovo, Prishtina, Kosovo \\ ${ }^{9}$ Institute of Kosovo Forensic Psychiatry, University Clinical Center of Kosovo, Prishtina, Kosovo \\ ${ }^{10}$ Department of Medical Biochemistry, University Clinical Center of Kosovo, Prishtina, Kosovo \\ ${ }^{11}$ Department of Psychiatry, University Hospital Centre Sestre Milosrdnice, Zagreb, Croatia \\ ${ }^{12}$ Department of Genetics and Bioengeneering, International Burch University, Sarajevo, Bosnia and Herzegovina \\ ${ }^{13}$ Department of Laboratory Diagnostics, University Hospital Center Zagreb, Zagreb, Croatia \\ ${ }^{14}$ Department of Psychiatry, Psychosomatics and Psychotherapy, Center of Mental Health, \\ University Hospital of Würzburg, Würzburg, Germany
}

received: 4.2.2019;

revised: 14.5.2019;

accepted: 29.5.2019

\section{SUMMARY}

Background: Previous research showed inconsistent results concerning a possible association between solute carrier family 6 member 3 (SLC6A3) gene polymorphisms and dopamine symptoms of posttraumatic stress disorder (PTSD). Several studies also indicate that the myelin basic protein $(M B P)$ gene is of importance in the etiology of several psychiatric disorders. The aim of this study was to investigate the relation of distinct SLC6A3 and MBP gene polymorphisms with PTSD and whether SLC6A3 and MBP genotypes contribute to PTSD symptom severity.

Subjects and methods: The study included 719 individuals who had experienced war trauma in the South Eastern Europe (SEE). Genotypes of variable number tandem repeat (VNTR) polymorphism within the SLC6A3 gene were assessed in 696 participants, and the single nucleotide polymorphism (SNP) rs12458282 located within the MBP gene region was genotyped in a total of 703 subjects. The Mini International Neuropsychiatric Interview, the Clinical Administrated PTSD Scale (CAPS) and Brief Symptom Inventory (BSI), were used for data collection.

Results: No significant differences concerning the investigated SLC6A3 and MBP polymorphisms was identifiable between PTSD and non PTSD participants. Also we could not detect significant influence of these distinct SLC6A3 and MBP alleles on the severity of PTSD symptoms (CAPS) or BSI scores. However, the results of MBP rs12458282 within the patients with lifetime PTSD may point to a possible correlation of the major allele $(T)$ with elevated CAPS scores.

Conclusions: Our results do not support an association of the analysed SLC6A3 and MBP gene polymorphisms with PTSD in war traumatized individuals. We found that there is a possibility for a correlation of the T allele rs 12458282 within the MBP gene with higher CAPS scores in lifetime PTSD patients which would need to be tested in a sample providing more statistical power.

Key words: posttraumatic stress disorder - SLC6A3 (DAT) gene - MBP gene

$* * * * *$

\section{INTRODUCTION}

Family and twin studies indicate the importance of genetics in the development of posttraumatic stress disorder (PTSD) as an extreme maladaptive response to terrible and traumatic events. People, who have family members with PTSD, are at higher risk for this disorder, compared to individuals whose family members were exposed to the similar traumatic events, but did not develop PTSD (Yehuda et al. 2001). Also, in recent years there has been increased interest in PTSD genetics and epigenetics in order to identify genes that predict 
who may develop PTSD or how best to treat the disorder (Almli et al. 2014). Modifications of the genes, such as a methylation may correlate with symptom severity of current PTSD (Ziegler et al. 2018). Clinical and molecular genetic studies showed a strong evidence for the importance of gene - environment interactions in PTSD etiology (Domschke 2012). Further studies point to the importance of other mental disorders in the etiology of PTSD (Koenen et al. 2008). According to neuroimaging studies, patients with PTSD may be subject to disregulations in the dopamine system (Charney 2004). The most important protein for regulating intracellular and extracellular dopamine levels is the dopamine transporter protein (DAT) (Masoud et al. 2015) which is encoded by the solute carrier family 6 member 3 (SLC6A3) gene on chromosome 5p15.3 (Vandenbergh et al. 1992). The most prominent polymorphism of SLC6A3 is a VNTR (variable number tandem repeat) in the 3 ' untranslated region (3'UTR). The alleles in this sequences may comprise three to 13 repeats, but, alleles spanning nine (9R) and ten $(10 \mathrm{R})$ repeats are the most common variants. Segman et al. (2002) found a correlation between life time PTSD and the 9R allele among Jewish populations who experienced different traumatic events. Also, there is a connection between allelic variation in SLC6A3 and PTSD diagnosis, especially with criterion D symptoms of PTSD (Drury et al. 2013). Carriers of 9R alleles have an increased risk for PTSD diagnosis than carriers of 10R (Chang et al. 2012). The proven impact of dopamine on many psychiatric diseases and certain psychological symptoms suggests that the analysis of genotype variations of its transporter gene may contribute to a better understanding of PTSD diagnosis and treatment.

While for a long time the myelin sheath only was thought to serves exclusively for functioning of axons, bat nowadays there is evidence, that myelin is involved in the metabolism of neurons and that environmental factors, such as stress, can substantially change the myelination of the central nervous system. Acordingly, myelination within the hippocampus is more prevalent among veterans with PTSD compared to that of traumatized but healthy (Chao et al. 2015). Myelinated axons are abundant in white matter but they occur are as well in gray matter too. Therefore, changes in myelination, could also influence changes of gray matter areas. For example, smaller gray matter regions of the hippocampus are associated with the severity of insomnia in people with PTSD (Mohlenhoff et al. 2014). Myelin basic protein (MBP) is the main component of the myelin sheath. MBP is involved in several functions, like the adhesion of the cytosolic surfaces multilayered compact myelin interaction with actin and tubulin as well as signal transmission among cells (Boggs 2006). Two classes of MBP proteins are known, classic MBP, which is specifically found in Shwann cells and the myelin shats of oligodentrocytes in the nervous system, and Golli MBP which is observed within the immune system, bone marrow and in the nervous system. The human MBP gene is located at chromosome position 18q22/23 chromosome (Kamholz et al. 1987). Many studies described the 18q-23 locus as important for bipolar disorder and suggest that this region contains genes involved in many psychiatric and cognitive disorders (Hampson al et. 1999). Previous findings showed that the C allele of the MBP SNP rs12458282 can be of importance for the psychiatric disorders, for example schizophrenia (Baruch et al. 2009). The aim of this study was to investigate a possible association of SLC6A3 and MBP gene polymorphisms with development and the symptoms of posttraumatic stress disorder.

\section{SUBJECTS AND METHODS}

\section{Subjects}

This study is a part of the South Eastern Europe PTSD Study where recruited 719 (mean age $49.4 \pm 7.9$; 487 males) individuals who had experienced war-related trauma in the SEE conflicts between 1991 and 1999 (Kulenovic et al. 2016). Data for this study were obtained in the period from 2013 to 2015 in the following five psychiatric centres which are all located in countries, whose population had experienced war-related trauma between 1991 and 1999: Zagreb in Croatia (1991-1992), Sarajevo, Tuzla and Mostar in Bosnia and Herzegovina (1992-1995), and Prishtina in the Republic of Kosovo (1999-1999). Recruiment of participans for this study was performed as previously described by Kulenovic et al. (2016). Only participants with an age of at least 16 and no more than 65 years at the time of traumatisation were included. Exclusion criteria were the presence of organic depression, epilepsy, psychotic symptoms, addiction, valproid acid use and intellectual disability.

Depending on diagnosis, all 719 participants were divided into three experimental groups: patients with diagnosed current PTSD ( $\mathrm{N}=218$; mean age 50.1 \pm 6.7 ; 157 males), remitted participants with lifetime PTSD symptoms $(\mathrm{N}=151$; mean age $49.5 \pm 8.2$; 98 males $)$ and healthy volunteers $(\mathrm{N}=350$; mean age $48.8 \pm 8.5 ; 232$ males) with no diagnosable PTSD.

\section{Ethical Votes}

Ethical votes at the participating clinical centre obtained between 2011 and 2013 on the basis of local translations of an information and consent form designed by the Würzburg center. All participants were informed and signed consent for participation in this study after they underwent an explanation according to the principles of the declaration of Helsinki (WMA 2013).

\section{Psychometric instruments}

Demographics, clinical history, medication, psychopathology, life events and coping styles were evaluated using standard psychometric instruments in local languages, PTSD diagnosis being made in accordance with DSM-IV. Interviews were performed by trained medical personnel (psychiatrists, psychologists or psychiatric 
residents). The presence or absence symptoms of symptoms of PTSD in the screening stage, was assessed using the Structured Clinical Interview M.I.N.I. (Mini International Neuropsychiatric Interview). The Clinician Administrated PTSD Scale (CAPS) (Blake et al. 1995) was used to make a categorical PTSD diagnosis and to assess the severity of symptom of PTSD. For the assessment of psychological symptoms we used the Brief Symptom Inventory (BSI) (Derogatis \& Melisaratos 1983). BSI is a self-assessment scale composed of nine categories of symptoms (somatisation, obsessive-compulsive, anxiety, depression, interpersonal sensitivity, hostility, phobic anxiety, paranoid ideation and psychoticism). It includes three global indices of distress (Global Severity Index, Positive Symptom Distress Index, and Positive Symptom Total), which measure the overall psychological distress level, the intensity of symptoms, and the number of self-reported symptoms. Each item is scored on response scale of 0 to 4 , where 0 $=$ not at all, $1=$ a little bit, $2=$ moderately, $3=$ quite a bit and $4=$ extremely. The cut-off points for clinically significant symptoms are for all scales at the T-score of the normative population sample of $\mathrm{T} \geq 0.63$. The reliability of the BSI for the present sample was high (Cronbach $\alpha=0.987$ ). We performed case-control analyses for each genetic variation by testing patients with either current or lifetime PTSD in combination versus the control individuals. Further, we analysed each of the two patients groups individually with regard to a correlation of the polymorphic sites with CAPS and BSI score levels.

\section{Molecular Analyses}

DNA was isolated from whole blood using the Flexi Gene Kit (QIAGEN, hidden, Germany) and stored until genotyping at $-80{ }^{\circ} \mathrm{C}$ as described (Kulenovic et al. 2016). Genotyping of the SLC6A3 VNTR was done according previously published protocols (Hünnerkopf et al. 2007).

The MBP variant rs12458282 was genotyped using a custom designed KASP genotyping assay (LGC, Berlin,
Germany). A PCR reaction including an end-point fluorescent read-out was done according to manufacturers' instructions in a CFX384 Touch Cycler (Biorad, Munich, Germany). Genotype analysis was performed using the CFX Manager Software.

\section{Statistical Analyses}

Statistics were performed using R v. 3.3.1, and PLINK 1.9. Both polymorphisms were polymorphous (minor allele frequency $(\mathrm{MAF})>10 \%$ ), reached a minimal genotyping call rate of $96 \%$ and did not deviate from Hardy-Weinberg equilibrium $\mathrm{p}>0.1$ ). Logistic regression (MBP) and the $\chi^{2}$ test (SLC6A3) were used for case control analyses combining both patient groups to be tested against the control individuals. Linear regression and the Mann-Whitney $U$ test, respectively, were carried out for analyses on CAPS and BSI scores within each of the two patient groups individually. The following models were tested in all phenotypes: additive allelic, dominant and recessive, as well as the genotypic model. Analyses regarding the SLC6A3 VNTR were only performed with the $9 \mathrm{R}$ and $10 \mathrm{R}$ alleles. Individuals homozygous for $10 \mathrm{R}$ were tested against the group of individuals with any other genotype combination. The significance level was Bonferroni adjusted for 23 variants that were analysed in total in the entire project $(\alpha=0.002)$.

\section{RESULTS}

In order to examine the influence of the SLC6A3 and MBP gene on the etiopathology of PTSD, we examined the SLC6A3 VNTR and the MBP SNP rs 1245828 in a case control study $(\mathrm{N}=719)$ and analysed additionally their influence on two PTSD linked questionnaires, CAPS and BSI, in patients suffering from either current or lifetime PTSD symptoms. The allele and genotype distributions for the analysed SLC6A3 and MBP gene polymorphisms in war traumatized participants are shown in Table 1 and Table 2.

Table 1. Allele and genotype distribution of the DAT VNTR gene polymorphism in sample of war traumatized (N=696)

\begin{tabular}{lccccc}
\hline \multirow{2}{*}{ Groups in sample } & \multicolumn{2}{c}{ Allele frequencies $(\mathrm{n})$} & \multicolumn{3}{c}{ Genotype distribution (n) } \\
& $9 \mathrm{R}$ & $10 \mathrm{R}$ & $10 / 10$ & $9 / 10$ & $9 / 9$ \\
\hline PTSD $(\mathrm{n}=359)$ & 178 & 540 & 208 & 124 & 27 \\
No PTSD $(\mathrm{n}=337)$ & 180 & 494 & 183 & 128 & 26 \\
& $\chi^{2}=0.668, \mathrm{df}=1, \mathrm{p}=0.414$ & & $\chi^{2}=0.986, \mathrm{df}=2, \mathrm{p}=0.611$ \\
\hline
\end{tabular}

PTSD - respondents with posttraumatic stress disorder; No PTSD - respondents without posttraumatic stress disorder; 9R - nine repeat allele of DAT; 10R - ten repeat allele of SLC6A3

Table 2. Allele and genotype for MBP variant rs12458282 in sample of war traumatized individuals (N=703)

\begin{tabular}{|c|c|c|c|c|c|}
\hline \multirow{2}{*}{ Groups in sample } & \multicolumn{2}{|c|}{ Allele frequencies (n) } & \multicolumn{3}{|c|}{ Genotype distribution (n) } \\
\hline & $\mathrm{C}$ & $\mathrm{T}$ & $\mathrm{T} / \mathrm{T}$ & $\mathrm{C} / \mathrm{T}$ & $\mathrm{C} / \mathrm{C}$ \\
\hline $\operatorname{PTSD}(n=356)$ & 224 & 488 & 170 & 148 & 38 \\
\hline No PTSD $(n=347)$ & $\begin{array}{c}199 \\
\chi^{2}=1.31 \\
\end{array}$ & $\begin{array}{c}495 \\
p=0.255\end{array}$ & \multicolumn{3}{|c|}{$\chi^{2}=2.60, \quad \mathrm{df}=2, \quad \mathrm{p}=0.642$} \\
\hline
\end{tabular}

PTSD - respondents with posttraumatic stress disorder; No PTSD - respondents without posttraumatic stress disorder 


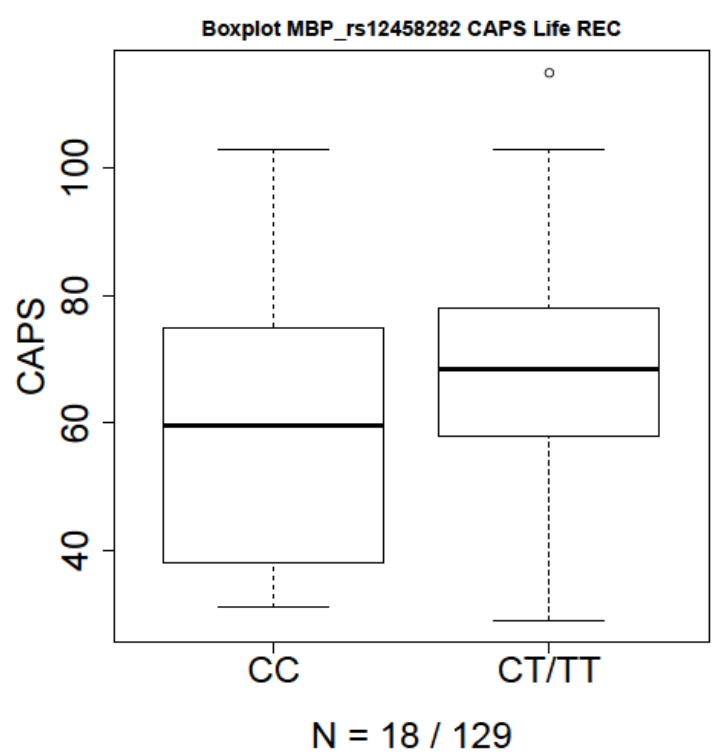

Figure 1. The distribution of CAPS scores within PTSD lifetime patients according to MBP rs12458282 genotypes $\mathrm{n}$ the dominant model for the $\mathrm{T}$ allele

\section{Solute carrier family 6 member 3 VNTR}

No significant differences of SLC6A3 VNTR genotype or allele distributions were detectable between PTSD cases and controls $\left(\mathrm{p}_{\text {all }}>0.1\right.$; Table 1$)$. Concerning the CAPS and BSI we did not identify an impact of SLC6A3 VNTR genotypes or alleles $(p>0.1)$ on the scores within the current or lifetime PTSD patient subgroups.

\section{Myelin Basic Protein rs12458282}

For MBP rs12458282 no significat associations were identified within allelic, genotypic-dominant and recessive models, neither for the dimensional CAPS and BSI traits or for the categorical phenotype of PTSD $\left(\mathrm{P}_{\mathrm{all}} \geq 0.05\right.$; Table 2). However, regarding the CAPS total score within the the lifetime PTSD patient subgroup our results may point to a posssible correlation of the $\mathrm{T}$ allele with higher scores $(p=0.079, \beta=-7.865, S E=4.451)$ but, they were not even passing the nominal significance level and were observed only in a dominant model of the $\mathrm{T}$ allele (Figure 1).

\section{DISCUSSION}

As we know, this is the first genetic research on PTSD in a South Eastern European population. Two studies, (Priebe et al. 2010, Lopes et al. 2003) have shown that there is a greater prevalence of PTSD in the region, compared with the prevalence in other parts of the world. Our results are inconsistent with previous published positive results there showed correlation in SLC6A3 gene polymorphisms and PTSD diagnosis (Segman et al. 2002, Drury et al. 2009, Chang et al. 2012, Valente et al. 2011). One reason for disagreement with results of Segman et al. (2002) could be that their sample comprised exclusively chronic forms of PTSD in their sample, while PTSD subjects in this study comprise the lifetime and current forms of PTSD. It is impossible to directly compare this results to results of Chang et al. (2012), because they suggest that myelination on SLC6A3 along with 9R allele probably leads to an elevated dopamine levels in the synaptic cleft, and risk of PTSD diagnosis. Also there is a difference in sample composition and methodology compared with Drury et al. (2009) and Drury et al. (2013), they worked with children who experienced different kinds of trauma. These results also indicate the possibility that $\mathrm{C}$ allele of the MBP SNP rs12458282 may be correlated with the severity of lifetime PTSD symptoms. However, a higher severity of symptoms was not a criterion during the recruitment of participants in this study. In addition, for the development of PTSD a combination of genetic and environmental factors is suggested. Further distinct changes of the volume of the hypocampus, and other brain regions, are not just specific for PTSD, as they observed in a lot of psychiatric disorders. Apart from the disorder itself, also duration and severity of the symptoms affect structural changes of the central nervous system. Hence, our results may imply the possibility that carriers of rs12458282 $\mathrm{T}$ allele who were exposed to trauma may develop PTSD over time, because we identified suggestive but not significant correlations with elevated CAPS scores in patients with lifetime PTSD diagnosis.

Limitations of this study can be that the sample comprises participants with a single type of trauma and that the sample size is relatively small. Also no data about a history of juvenile mental disorders was collected. This could be important because psychiatric disorders in childhood may determine which subjects have a risk for developing PTSD (Koenen et al. 2008). Other studies with larger samples and with more specific data about the severity of PTSD symptoms are needed to extend knowledge about the etiology of this frequently observed disorder.

\section{CONCLUSIONS}

The present study has shown that neither MBP nor SLC6A3 polymorphisms are significantly correlated with PTSD diagnosis. However, our results indicate that there is a possibility for correlation between an elevated CAPS score and T allele of MBP gene in patients with remitted PTSD.

\section{Conflict of interest: None to declare.}

\section{Contribution of individual authors:}

Each author has actively participated in the international research project (see Acknowledgments) and, therefore, has substantially contributed to the development and publication of this manuscript. 


\section{Acknowledgements:}

We thank all the participants and their families without whose idealistic and enthusiastic support the study would not have been possible. We also would like to thank at Sarajevo: the Association of Women Victims of War and Bakira Hasecic, the Association of Physically Handicapped, Zilko Buljugija, Zoran Budimlija, MD, PhD, Jasminka Krehic, MD, PhD, Elvira Sabanovic, RSN and Subhija Gusic; in Kosovo: Feride Rushiti, MD, Selvije Izeti, MSc, Vjosa Devaja, MD, Melita Kallaba, MD from Kosova Rehabilitation Center for Trauma Survivors- KRCT; Emirjeta Kumnova, Veprore Shehu from Medica Kosova; Zahrije Podrimqaku Subashi from the Association of Political Prisoners, Kadire Tahiraj from the Center for Promotion of Women's Rights; Arbërore Ulaj, MD, Teuta Haxhiu, MD and Drita Gashi, MD, for their assistance in recruiting and interviewing participants; at Zagreb: Mirica Mavracic, Zoran Bradas, Zrinka Mirkovic and Maja Mezak Herceg for technical assistance in drawing blood and extracting DNA; at Tuzla: the staff of the Department of Transfusion of University Clinical Center of Tuzla, and the staff of the Department of Psychiatry, in particular Emina Hujdur, Medin Omerašević and Avdo Šakušić, MD for technical support and Maja Brkić and Sandra Zornić for their assistance in data collection; at Würzburg: Carola Gagel for technical assistance with extracting DNA. Thanks are highly deserved by and gratefully extended to Peter Riederer as spiritus rector who brought the consortium together. The study was funded by the DAAD program Stability Pact for South Eastern Europe and supported by the DFG-funded RTG 1253 (speaker Pauli) as well as the DFG-funded CRC-TRR58 (projects C02 Domschke, Deckert, and Z02 Deckert, Domschke)

Conflict of interest: None to declare.

\section{Contribution of individual authors:}

Each author has actively participated in the international research project (see Acknowledgments) and, therefore, has substantially contributed to the development and publication of this manuscript.

\section{References}

1. Almli LM, Fani N, Smith AK \& Ressler KJ: Genetic approaches to understanding posttraumatic stress disorder. Int J Neuropsychopharmacol 2014; 17:355-370 doi:10.1017/S1461145713001090

2. Baruch K, Silberberg G, Aviv A, Shamir E, Bening-AbuShach U, BaruchY et al.: Association between Golli-MBP and schizophrenia in the Jewish Ashkenazi population: are regulatory regions involved? Int $J$ Neuropsychopharmacol 2009; 885-94

3. Blake DD, Weathers FW, Nagy LM, Kaloupek DG, Gusman FD, Charney DS et al.: The development of a clinician-administrated PTSD scale. J Trauma Stress 1995; 8:75-90

4. Boggs JM: Myelin basic protein: a multifunctional protein. Cell Mol Life Sci 2006; 63:1945-61

5. Chang SC, Koenen KC, Galea S, Aiello AE, Soliven R, Wildman DE et al.: Molecular variation at the SLC6A3 locus predicts lifetime risk of PTSD in the Detroit Neighborhood Health Study. PLoS One 2012; 7:e39184

6. Chao LL, Tosun D, Woodward SH, Kaufer D \& Neylan TC: Preliminary Evidence of Increased Hippocampal Myelin Content in Veterans with Posttraumatic Stress
Disorder. Front Behav Neurosci 2015; 9:333. doi: 10.3389/fnbeh.2015.00333

7. Charney DS: Psychobiological mechanisms of resilience and vulnerability: implications for successful adaptation to extreme stress. Am J Psychiatry 2004; 161:195-216

8. Derogatis L, Melisaratos N. The Brief Symptom Inventory: A introductory report. Psychological Medicine 1983; 13:595-605

9. Domschke K: Patho-Genetics Of Posttraumatic Stress Disorder. Psychiatr Danub 2012; 24:267-273

10. Drury SS, Theall KP, Keats BJB \& Scheeringa M: The Role of the Dopamine Transporter (DAT) in the Development of PTSD in Preschool Children. J Trauma Stress 2009; 22:534-539. doi:10.1002/jts.20475

11. Drury SS, Brett ZH, Henry C \& Scheeringa M: The association of a novel haplotype in the dopamine transporter with preschool age posttraumatic stress disorder. J Child Adolesc Psychopharmacol 2013; 23:236-43

12. Hampson RM, Malloy MP, Mors $O$, Ewald H, Flannery $A V$, Morten $J$ et al.: Maping studies on a pericentric inversion (18) (p11.31 q21.1) in a family with both schizophrenia and learning disability. Psychiatric Genetics 1999; 9:161-163

13. Hunnerkopf R, Strobel A, Gutknecht L, Brocke B \& Lesch $K P$ : Interaction between BDNF Val66Met and Dopamine Transporter Gene Variation Influences Anxiety-Related Traits. Neuropsychopharmacology 2007; 32:2552-2560

14. Kamholz J, Spielman R, Goglin K, Modi W, O'Brien $S$ \& Lazzarini R: The Human Myelin-Basic-Protein Gene: Chromosomal Localization and RFLP Analysis. Am J Hum Genet 1987; 40:365-373

15. Koenen KC, Moffitt TE, Caspi A, Gregory A, Harrington $H$ \& Poulton R: The Developmental Mental-Disorder Histories of Adults With Posttraumatic Stress Disorder: A Prospective Longitudinal Birth Cohort Study. J Abnorm Psychol 2008; 117:460-466. doi:10.1037/0021-843X.117.2.460

16. Kulenovic AD, Agani F, Avdibegovic E, Jakovljevic M, Babic D, Kucukalic A et al.: Molecular Mechanisms of Posttraumatic Stress Disorder (PTSD) as a Basis for Individualized and Personalized Therapy: Rationale, Design and Methods of the South Eastern Europe (SEE)PTSD study. Psychiatr Danub 2016; 28 2:154-63

17. Lopes Cardoso B, Kaiser R, Gotway CA \& Agani F: Mental Health, Social Functioning and Feelings of hatred and Revenge of Kosovar Albanians one Year After the War in Kosovo. J Trauma Stress 2003; 16:351-60

18. Masoud ST, Vecchio LM, Bergeron Y, Hossain MM, Nguyen LT, Bermejo MK et al.: Increased expression of the dopamine transporter leads to loss of dopamine neurons oxidative stress and L-DOPA reversible motor deficits. Neurobil Dis 2015; 74:66-75

19. Mohlenhoff BS, Chaoa LL, Buckleyc ST, Weinera $M W \&$ Neylana TC: Are hippocampal size differences in posttraumatic stress disorder mediated by sleep pathology? Alzheimers Dement 2014; 10:S146-S154. doi:10.1016/j.jalz.2014.04.016

20. Priebe S, Bogic M, Ajdukovic D, Franciskovic T, Galeayyi GM, Kucukalic A et al.: Mental disorders following war in the Balkans: A studdy in five countries. Arch Gen Psychiatry 2010; 67:518-528 
21. Segman RH, Cooper-Kazaz R, Macciardi F, Goltser T, Halfon Y, Dobroborski $T$ et al.: Association between the dopamine transporter gene and posttraumatic stress disorder. Mol Psychiatry 2002; 7:903-907

22. Valente NL, Vallada H, Cordeiro Q, Miguita K, Bressan RA, Andreoli SB et al.: Candidate-gene approach in posttraumatic stress disorder after urban violence: association analysis of the genes encoding serotonin transporter, dopamine transporter, and BDNF. J Mol Neurosci 2011; 44:59-67

23. Vandenbergh DJ, Persico AM, Hawkins AL, Griffin CA, Li $X$, Jabs EW et al.: Human dopamine transporter gene
(DAT1) maps to chromosome 5p15.3 and displays a VNTR. Genomics 1992; 14:1104-6

24. Yehuda R, Halligan SL \& Grossman R: Childhood trauma and risk for PTSD: Relationship to intergenerational effects of trauma, parental PTSD, and cortisol excretion. Dev Psychopathol 2001; 13:733-53

25. Ziegler C, Wolf C, Schiele MA, Bojic EF, Kucukalic S, Dzananović ES et al.: Monoamine Oxidase A Gene Methylation and Its Role in Posttraumatic Stress Disorder: First Evidence from the South Eastern Europe (SEE)-PTSD Study. Int J Neuropsychopharmacol 2018; 21:423-432

Correspondence:

Mirnesa Muminovic Umihanic, MD

Community Health Center Zivinice

Alije Izetbegovica 17, 75270 Zivinice, Bosnia \& Herzegovina E-mail:mirnesa_1@hotmail.com 